\title{
A MIXT RELAXATION ALGORITHM APPLIED TO QUASI-VARIATIONNAL INEQUATIONS
}

\author{
J.C. MIELLOU \\ Eaculté des Sciences et des Techniques \\ La Bouloie - Route de Gray \\ 25030 - BESANCON CEDEX
}

Introduction -

In the first paragraph we consider a class of finite dimensionnal quasi-

variationnal inequalities problems, for which we recall a "Theoretical" algorithm allowing the approximation of a maximal inequalities. Then we recall an heuristic formulation of a method which mixt point relaxation method and the "Theoretical" algorithm mentionned above,

In the second paragraph we introduce in a more general frame (Block-relaxation), a precise formulation and set convergence results for this mixt method. For this purpose we use a notion of "delays" previousiy introduced by CHAZAN and MIRANKER, in the formulation of multiprocessor relaxation algorithms.

$\S I$ - BACKGROUND : definitions, a finite dimensional I.Q.V. problem; a "Theoretical" algorithm : First formulation of a mixt GAUSS-SEIDEL algorithm. Let BEN, $\mathrm{E}=\mathrm{R}^{\mathrm{S}}, \mathrm{K}=\mathrm{R}^{\mathrm{S}}+$

We note s the partial order relation induced on $E$ by the cone $K$. We consider the application to :

$v=\left\{v_{1}, \ldots, v_{k}, \ldots, v_{\beta}\right\} \in R^{\beta} \stackrel{d t}{\longrightarrow} A(v)=\left\{d t_{1}(v), \ldots, t_{\ell}(v), \ldots, t_{\beta}(v)\right\} \in R^{\beta}$.

For $k \in\{1, \ldots, B\}$ let $\ell_{k}=\{0, \ldots, 0,1,0, \ldots, 0\} \quad \forall k, 1 \in\{1, \ldots, \beta\}$ we consider the function $\forall t \in R \stackrel{\varphi_{k, I}}{\longrightarrow} \varphi_{k, 1}(t)=t_{1}\left(v+t e_{k}\right)$.

Definition 1 -

The application th is an M-application (or M-function) if:

For $k \neq i \quad t \rightarrow \varphi_{k, l}(t)$ is antitone and moreover:

$$
t_{0}(u) \leqslant t_{0}(v) \Longrightarrow u \leqslant v \text {. }
$$

Definition 2 -

The application to is an L-application if:

$\exists\left\{\lambda_{1}, \ldots, \lambda_{\beta}\right\} \in K$ such that $f+\Lambda$ be an M-opplication from $R^{\beta}$ onto $R^{\beta}$ where is defined by :

$v=\left\{v_{1}, \ldots, v_{2}, \ldots, v_{B}\right\} \stackrel{\Lambda}{\longrightarrow} A v=\left\{\lambda_{1} v_{1}, \ldots, \lambda_{2} v_{2}, \ldots, \lambda_{B} v_{B}\right\}$.

Let $\left\{u^{p}\right\}$ be a sequence of vectors $\left(\forall p \in N \quad u^{p} \in R^{B}\right.$ ), we note the fact that

$\left\{u^{p}\right\}$ is isotone (resp, antitone) and converges towards $u$, by $u^{p} u_{u}$ (resp. $u^{P_{u}} u$ ). 
Définition 3 -

Let a mapping $g: R^{\beta} \rightarrow R^{\beta}$ be isotone, $g$ is o-half-continuous on the right (resp. the left) if :

(1.1) $u^{p}+u\left(\operatorname{resp} u^{p}+u\right) \quad g\left(u^{p}\right)+g(u) \quad\left(\operatorname{resp} g\left(u^{p}\right)+g(u)\right)$.

Remark - Definition 1 is due to W.C. RHEINBOLDT, property (1.1) that we call here o-half-continuity is due to BENSOUSSAN-GOURSAT-LIONS.

we consider now the hypothesis :

Let $t: R^{\beta} \rightarrow R^{\beta}$ be a continuous mapping which is an L-application ; and let $f \in R^{B}$.

Let $\Phi K \rightarrow K$ be isotone for the order induced on $R^{\beta}$ by $K$, and O-halfcontinuous on the right on $k$.

(1.4) $\forall w^{\prime} \in K$ Let $U_{\left(w^{\prime}\right)}=\left\{v \in K \mid v \leqslant \Phi\left(w^{\prime}\right)\right\}$.

We formulate the I.Q.V. problem - (I.Q.V. for quasi-variationnal inequalities)

(1.5) a $\left\{\begin{array}{l}\text { Find } u \in U_{(u)} \text { such that: } \\ \left(H_{(}(u), v-u\right) \geqslant(f, v-u) \quad \forall v \in U_{(u)}\end{array}\right.$

(where (,) notes the usual scalar product on $R^{\beta}$ ).

Other formulation of problem $(1.5)_{a}: \forall w^{\prime} \in K$, we mark $\Phi^{\prime}\left(w^{\prime}\right)=\left\{\ldots, \Phi_{w^{1}}^{\perp}, \ldots\right\}$ for $1 \in\{1, \ldots, \beta\}$.

Let $\Psi\left[O, \Phi_{W^{\prime}}^{I}\right]$ is the indicatrix function of the segment $\left[0, \begin{array}{l}1 \\ W^{1}\end{array}\right]$, and let $\partial \Psi \quad\left[0, \Phi_{W^{1}}^{1}\right] W^{\top}$ be the sub-differential of $\Psi\left[0, \Phi_{W}^{1}\right]$.

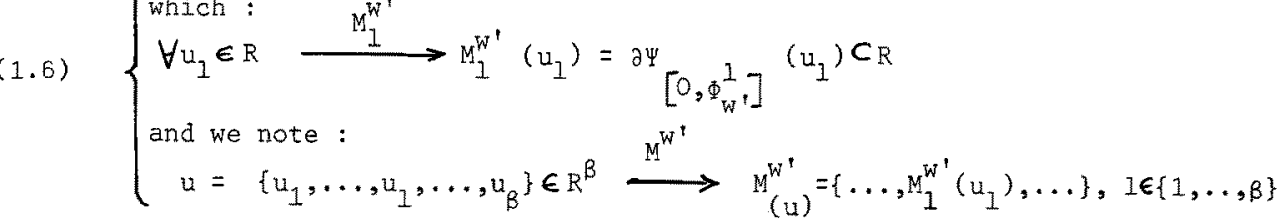
$\left(M^{W '}\right.$ is an operator of diagonal type).

The problem (1.5) a can now be formulated in the following manner :

$(1.5)_{b}\left\{\begin{array}{l}\text { Find } u \in D\left(M^{u}\right) \text { such that } \\ 0 \in M^{u}(u)+d(u)-f .\end{array}\right.$

A "Theoretic" algorithm for the approximation of" a solution of problem (1.5) a/on b/ Starting from a convenient initial vector $u^{\circ}$, we consider a sequence of

I.V. problems (for Variationnal Inequaities):

(1.7) $)_{a}\left(d\left(u^{p+1}\right), v-u^{p+1}\right) \geqslant\left(f, v-u^{p+1}\right) \quad \forall v \in \mathcal{U}\left(u^{p}\right), \quad p=0,1, \ldots$

These kind of algorithm has been proposed and studied by BENSOUSSAN, GOURSAT, LIONS in the continuous case (A being then an elliptic second order, partial differential 
operator).

We can also formulate the problems (1.7) a in the following manner.

$(1.7)_{b} \quad 0 \in M^{u^{p}}\left(u^{p+1}\right)+t\left(u^{p+1}\right)-f^{a} \quad p=0,1, \ldots$

First formulation of a mixt GAUSS-SEIDEL algorithm -

BENSOUSSAN - LIONS (see also the work of COMMINCIOLI and alt for analogous free boundary problems) had proposed for the resolution of each problem (1.5) $a /$ or b/ the point GAUSS-SEIDEI method with projection, which can be formulated by : let $u^{O}, P=u^{P}$ we approximate $u^{p+1}$ by a sequence $\left\{u^{Q, p}\right\}$ defined by :

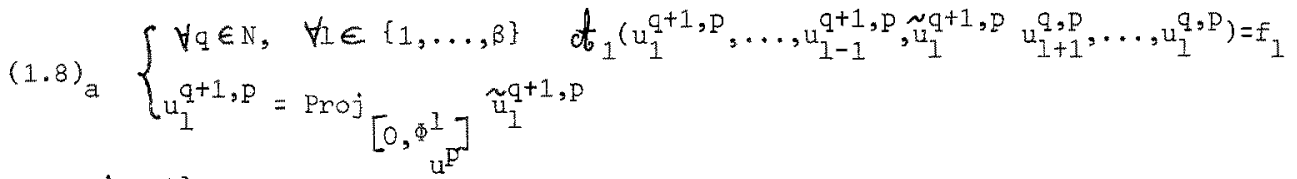
or equiventiy:

$(1.8)_{b} \quad \forall c \in N, \quad \forall I \in\{1, \ldots, \beta\} \quad o \in M_{1}^{u_{p}}\left(u_{1}^{q+1}, p\right)+A_{1}\left(u_{1}^{q+1}, p, \ldots, u_{1}^{q+1}, p, u_{1+1}^{q}, \ldots\right)$ $-\mathrm{F}_{1}$

For q "great" we replace in $(1.8) a /$ or $b / u_{p}$ by $u^{q, p}$ and start again, in (1.8) a) on b/, with $u^{o, p+1}=u^{q, p}$.

Here it must be observed that $\mathrm{u}^{0, p+1} \neq \mathrm{u}^{\mathrm{p}+1}$ so we cannot by the use of GAUSSSEIDEL algorithm for the approximation of I.V. subproblems obtain exactly the "theoretical" algorithm (1.7).

\section{§ II - FORMULATION OF A MIXT RELAXATION ALGORITHM USING A NOTION OF DELAYS -}

Our main interest is now : To give a precise formulation of a mixt algorithm allowing the association of the "Theoretical" algorithm (1.7), and relaxation methods (namely under-relaxation and GAUSS-SEIDEL); moreover we place ourselves in a little more general frame, than a bove : that is to say, block-relaxationmethods.

Subproblems associated to problem (1.5) (2.1) $\left\{\begin{array}{l}\text { Let } \alpha \in N \text { such that } \alpha \leq \beta, \text { and a family of integers }\left\{\beta_{1}, \ldots, \beta_{i}, \ldots, \beta_{\alpha}\right\} \\ \text { such that } \sum_{i=1} \beta_{i}=\beta .\end{array}\right.$

(2.2) $\left\{\begin{array}{l}\forall i \in\{1, \ldots, \alpha\} \quad E_{i}=R^{\beta_{i}} \text { and } \leqslant \text { is the relation of partial order indu- } \\ \text { ced by the cone } k_{i}=R_{+}^{\beta} \text { then } E_{i}=\prod_{i=1}^{\alpha} E_{i} ; k=\prod_{i=1}^{\alpha} k_{i} .\end{array}\right.$ $\forall w^{\prime} \in \mathrm{E}, \quad \forall i \in\{1, \ldots, \alpha\} \quad$ Let :

$U_{(w)}^{i}=\left\{v_{i} \in K_{i} \subset E_{i} \mid v_{i} \Phi_{i}^{i}=\left\{\ldots, \Phi_{w}^{1}, \ldots\right\}\right.$ for $1 \in\left\{\beta_{1}+\ldots+\beta_{i-1}-1, \ldots, \beta_{1}+\right.$ we note moreover :
$\forall i \in\{1, \ldots, \alpha\} \quad u_{i} \in E_{i} \stackrel{M_{i}^{W^{p}}}{\longrightarrow}-N_{i}^{W^{i}}\left(u_{i}\right)=\left\{\ldots, M_{1}^{W^{p}}\left(u_{1}\right), \ldots\right\}$, for 


$$
1 \in\left\{\beta_{1}+\ldots+\beta_{i-1}+1, \ldots, \beta_{1}+\ldots+\beta_{i}\right\} .
$$

$\forall u=\left\{u_{1}, \ldots, u_{i}, \ldots, u_{\alpha}\right\} \in \prod_{i=1}^{\alpha} \quad E_{i}$

Let $t(u)=\left\{\operatorname{ctg}_{1}(u), \ldots, \mathrm{dt}_{j}^{i=1}(u), \ldots, t_{\alpha}(u)\right\} \in \prod_{j=1}^{\alpha} E_{j}$

$\forall w=\left\{w_{1}, \ldots, w_{j}, \ldots, w_{\alpha}\right\} \in \prod_{j=1}^{\alpha} \quad E_{j}, \forall u_{j} \in E_{i}$

Let $a_{i, w}\left(u_{i}\right)=A_{i}\left(w_{1}, \ldots, w_{i-1}, u_{i}, w_{i+1}, \ldots, w_{\alpha}\right)$

Let $(\mathbb{H})=\left\{\theta_{1}, \ldots, \theta_{j}, \ldots, \theta_{\alpha}\right\} \in \mathbb{j}_{j=1}^{\alpha}[0,+\infty[$ such that :

(2.3) $\forall i \in\{1, \ldots, \alpha\} \quad \theta_{j} \geqslant \max _{\beta_{1}+\ldots+\beta_{j-1}^{<1 \leqslant \beta_{1}}+\ldots+\beta_{j}} \lambda_{1}$

where $\left\{\lambda_{1}, \ldots, \lambda_{\beta}\right\}$ has been introduced in definition 2 .

We consider also $\Omega=\left\{\omega_{1}, \ldots, \omega_{j}, \ldots, \omega_{\alpha}\right\} \in \underset{j=1}{\alpha}[0,1]$ such that :

$\forall j \in\{1, \ldots, \alpha\} \quad$ either $\omega_{j}=1$, or $d_{j} \in R, \quad d_{j}>0$ such that

(2.4) $\forall w \in R^{\beta}, \quad \forall v_{j}^{1}, v_{j}^{2} \in R^{\beta} j \quad$ with $\quad v_{j}^{1} \leqslant v_{j}^{2}$.

$a_{j, w}\left(v_{j}^{2}\right)-a_{j, w}\left(v_{j}^{1}\right) \leqslant d_{j}\left(v_{j}^{2}-v_{j}^{1}\right)$ and $\left(1-w_{j}\right) d_{j} \leqslant \theta_{j}$.

we considen now the subproblems :

$(2.5) a\left\{\begin{array}{l}\forall w, w^{\prime} \in K_{,}, \forall j \in\{1, \ldots, \alpha\} \quad \text { find } u_{j} \in \mathcal{U}_{\left(w^{\prime}\right)}^{j} \text { such that : } \\ \left(a_{j, w^{\prime}}\left(w_{j} u_{j}+\left(1-w_{j}\right) w_{j}\right)+\theta_{j}\left(u_{j}-w_{j}\right), v_{j}-u_{j}\right) \geqslant\left(f_{j}, v_{j}-u_{j}\right) \forall v_{j} \in \mathcal{U}_{\left(\bar{w}^{\prime}\right)}^{j} \\ \left.\text { where }(,)_{j} \text { is the usual scalar product on } E_{j}=R{ }^{\beta_{j}}\right) .\end{array}\right.$

which can also be formulated by :

$\forall w, w^{\prime} \in K \quad \forall j \in\{1, \ldots, \alpha\} \quad$ find $u_{j} \in D\left(M_{j}^{W^{2}}\right)$. such that :

$(2.5)_{b} \quad f_{j} \in M_{j}^{w}\left(u_{j}\right)+a_{j, w}\left(w_{j} u_{j}+\left(1-w_{j}\right) w_{j}\right)+\theta_{j}\left(u_{j}-w_{j}\right)$

and we wright :

\section{Proposition 1 -}

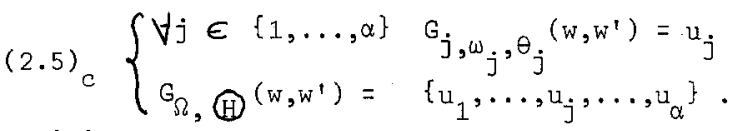

The hypothesis (1.2), (1.3), (1.4), (2.1), (2.2), (2.3) being satisfied,

w, $w^{\prime} \in K \longrightarrow G_{\Omega,(\Theta)} \rightarrow G_{\Omega},(1)\left(w, w^{\prime}\right)$ is well defined (i.e. $\exists$ a unique solution of each subproblem (2.5) a/ or $b /$ ', is an isotone mapping of each of its two arguments $w$, $w$ ', and is continuous relatively to the first argument $w$, and half-continuous on the might relatively to the second argument $w^{\prime}$. Moreover $u \in K$ is a solution of the I.Q.V. probiem (1.5) a/ or $b$ / iff $u$ is a fixed point of the application:

$$
\left.w \stackrel{F}{\longrightarrow} F(w)=G_{\Omega, ~}\right)^{(w, w)}
$$


Mixt algorithm associating "theoretieal" algorithm (1.7) and relaxation methods -

Fon the sake of simplicity we suppose that we want to perform $r$ relaxation iterations for the approximation of the solution of each I.V. occuring in the "Theoretical" algorithm $(1.7) \mathrm{a}$ " $\mathrm{u}^{\circ}$ being conveniently choiced (the precise choice shall begiven in proposition 2/) we introduce now three formulation of the same following mixt algorithm :

let $h(p)=p \bmod (\alpha)+1 ; k(p)=p \bmod (r \alpha)$.

$(2.6)_{a}\left\{\begin{array}{l}\text { If } \quad j \neq h(p) \quad u_{j}^{p+1}=u_{j}^{p} \\ \text { If } \quad j \neq h(p) \quad \text { find } u_{j}^{p+1} \in U^{j}\left(u^{p-k(p)}\right) \\ \left(a_{j, u p}\left(w_{j} u_{j}^{p+1}+\left(1-w_{j}\right) u_{j}^{p}\right)+\theta_{j}\left(u_{j}^{p+1}-u_{j}^{p}\right), v_{j}-u_{j}^{p+1}\right)_{j} \geqslant\end{array}\right.$

$$
\left.\left(f_{j}, v_{j} u_{j}^{p+1}\right)_{j} \quad \forall v_{j} \in \mathcal{U}_{(u}^{j} p-k(p)\right)
$$

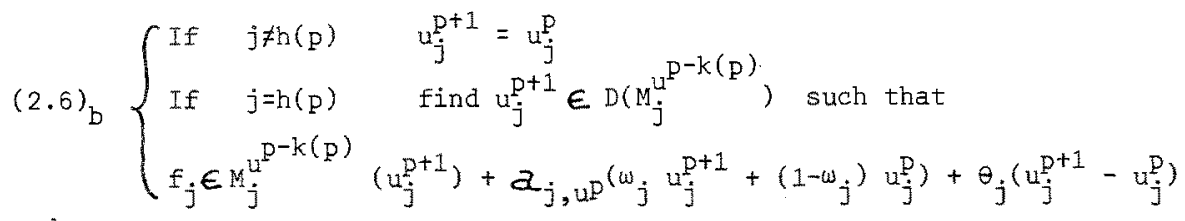

and :

$(2.6)_{c}\left\{\begin{array}{lll}i f & j \neq h(p) & u_{j}^{p+1}=u_{j}^{p} \\ i f & j=h(p) & u_{j}^{p+1}=G_{j, \omega_{j}, \theta_{j}}\left(u^{p}, u^{p-k(p)}\right) .\end{array}\right.$

\section{Proposition 2 -}

The hypothesis are the some that those of proposition 1 , and let $u^{\circ} \in K$, be such that $f \leqslant$ oto $\left(u^{0}\right)$, then the sequence $\left\{u^{p}\right\}$ produced by algomithm $(2.6) a / b /$ or $c /$ is such that $u^{p}+u$ maximal solution of problem $(1.5)$ af or $b /$, and fixed point of $w \stackrel{E}{*}+E(w)=G_{\Omega, \Theta}\left(w_{3} w\right)$

Remarks - Il we cancel the constraints of our problem and :

- take $\alpha=1$ and so $\beta_{1}=\beta$ we can give an interpretation of algorithm $(2.6)$ by the scheme :

$\frac{u^{p+1}-u^{p}}{k}+d\left(w u^{p+1}+(1-w) u^{p}\right)-f=0$

( Taking $\theta=\frac{1}{k}$ ).

as the discretisation of :

$\frac{d u}{d t}+t(u)-f=0 \quad u(0)=u^{0}$

- take $\alpha=\beta$ and suppose that $d s$ is a matrix with diagonal elements a11. equals to 1 then we find the classical relaxation method with relaxation parameters $\frac{1}{\omega_{j}+\theta_{j}}$ and hypothesis $(2.4)$ implies that we are here in the case of under relaxation and GASS-SEIDEL methods.

- The sequence $\{k(p)\}$ constitutes the "delays" : notion introduced by CHAZAN- 
MIRANKER for multiprocessors relaxation algorithms which can also be mixted with "Theoretical algorithm" (1.7) in the following manner :

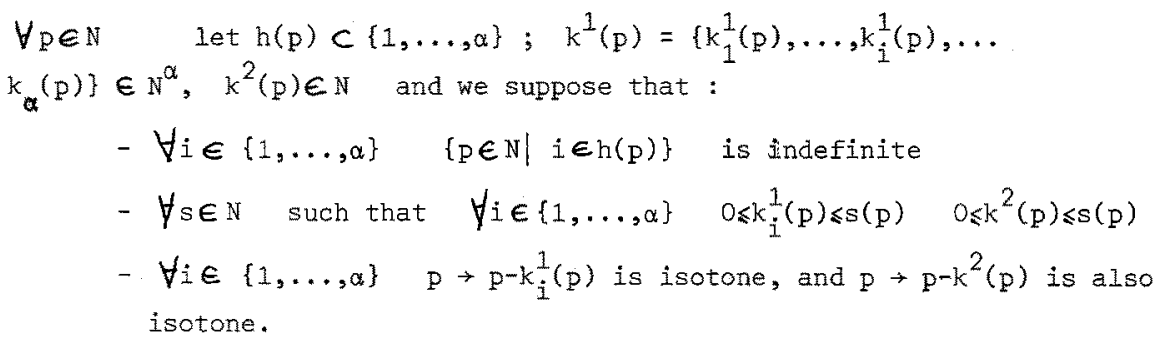

Then we consider the algorithm :

$$
\begin{aligned}
& u_{j}^{p+1}=G_{j}\left(\ldots, u_{i}^{p-k_{i}^{1}(p)}, \ldots, u^{p-k^{2}(p)}\right) \text { if } j=h(p) \\
& u_{j}^{p+1}=u_{j}^{p} \quad \text { if } j \neq h(p)
\end{aligned}
$$

Proposition 2 extends without difficulties to this more general situation.

It seems that a particular interest of block relaxation methods in quasirvariation nal inequation problems lies in the fact that, these problems being often of great size, it can be necessary to decompose the arrays, which contain iterates vectors, in sub arrays corresponding to block'sub problems, which can be contained in central memory of the processor used. Block relaxation can be interpreted as an iterative coordination method between these subproblems, which needs relatively simple (sequential), exchanges between central memory, and peripheral memories (disks).

\section{BIBLIOGRAPHIE}

ALBRECHT, J.

Fehlerschranken und konvergenzbescheunigung Bei einer Monotonen oder Alterniendev iterationsfolge.

Numer. Math., fi, (1962), 198-208.

BAIOCCHI, C. ; COMINCIOLI, V. ; GUERRI, L. ; VOLPI, G.

Free boundary problems in the theory of fluid flow through pourous media : a

numerical approach.

Calcolo 10, (1973), 1-86.

BENSOUSSAN, A. ; GOURSAT, M. ; LIONS, J.L.

C.R. Acad. Sci. PARIS Sér. A, (1973), 1279.

BIRKHOFF, G. ; KELLOGG, R.

Solution of equilibrium equations in thermal networks.

Proc. Symp. generalized Networks BROOKLYN, (1966), 443-452. BOHL.

Nichtlineare aufgaben in halb geordneten raumen.

Numex. Math. 10, (1964), 220-231. 
CHARNAY, M.

Itérations chaotiques sun un produit d'espaces.

C.R. Acad. Sci. PARIS, t. 279, (1964).

CHARNAY, M. ; MUSY, F. ; ROBERT, F.

Itérations chaotiques série-parallèle pour des équations non linéaires de point

fixe. A paratire dans Aplikace Mathematiky.

CHARNAY, M.

Thèse de 3ème cycle, Université Claude Bernard, LYoN (1975).

CHARNAY, M. ; MUSY, $匚$.

Sur le théorème de Stein-Rosenberg.

R.A.I.R.O., R-2, (1284), 95-108.

CHAZAN, D. ; MIRANKER, W.

Chaotic nelaxtion.

Linear algebra and its appl., 2, (1969), 199-222.

COLLATZ, L.

Functional analysis and numerical mathematics.

Springer Verlag, Berlin, Tranz. by H. OSER, Acad. Press, New-York, (1966).

DONNELLY, J.D.P.

Periodic chaotic relaxation.

Iinear algebra and its appl., 4, (1971), 117-128.

DURAND, J.F.

L'algorithme de Gauss-Seidel appliqué à un problème unilatéral non symétrique.

R.A.I.R.O., R-2, (1972), 23-30.

FIORIOT, J.-Ch.; HUARD, P.

Relaxation chaotique en optimisation.

Publication du Laboratoire de Caloul de l'Université de Litze, (1974).

GORENFLO, R. ; SCHAUM, H.J.

Monoton einschliessende Iterationsverfahren für invers-isotone diskretisierung

nicht-linearer Zwei-Punkt-Randwertaufgaben zweiter Ordnung.

Lectures Notes in Math., 395, Springer-Vertag, Berlin, (1974), 177-198. KANTOROVICH, L.

The method of successive approximations for functionnal equations.

Acta Math., 71, (1939), 63-97.

KRASNOSELSKII.

Approximate solution of operator equations.

Walters Nordhoff Publishing Groningen, (1972).

LEGAY.

Exposé au colloque sur les méthodes numériques en calcul scientifique et technique.

AFEET, Chatenay-MaLabry, Nov. 1974. 
MAURIN.

Exposé à la 7 th IFIP Conference on optimisation techniques.

NICE, Septembre 1975.

MIELLOU, J.C.

C.R. Acad. Sci. PARIS, 278, sêmie A, (1974), p. 957.

MIELLOU, J.C.

Exposé au séminaire IMAG (Univ. de GRENOBLE, avmil 1974), et au Colloque National d'Analyse Numérique de GOURETTE, Juin 1974.

MIELLOU, J.C.

C.R. Acad. Sci. Paris, 280, sémie A, (1975), 233-236.

MOSCO, U. ; SCARPINI, F.

Complementarity systems and approximation of variational inequalities.

R.A.I.R.O., R-1, gème année, (1975), 83-104.

ORTEGA, J.M. ; RHEINBOLDT, W.C.

Iterative solution of non linear equations in severale variables.

Academic Press, (1970).

OSTROWSKI, A.

Determination mit überwiegender Haupt diagonale und die absolute Konvergenz von linearen Iterationsprozessen.

Commin. Math. Helv, , 30, (1955), 175-210.

PORSHING, T.

Jacobi and Gauss-Seidel Methods for non linear network problems.

SIAM J. Numex. Araz. 6, (1969), 437-449.

RHEINBOIDT, W.C.

J. Math. Anal. and Appl. 32, (1970), 274-307,

ROUX, J.

EDF, Bulletin de la direction des études et recherches. Série C, Math.-Inform.,

$n^{\circ} 2,(1972), 77-90 ; n^{\circ} 1,(1973), 43-54$.

SCHECHTER, $S$.

Relaxation methods for linear equations.

Commun. Pure and Appl. Math., 12, (1959), 313-335.

SCHECHTER, S.

Iteration methods for non linear problems.

Trans. AMS, 104, (1962), 179-189.

SCHRODER, J.

An wendung von fixpunksatzen bei der numerischen behandlung nichtlinearen glei-

chungen in halb geordneten raumen.

Arch. National Mech. Anat., 4, 177-192.

TARTAR, L.

C.R. Acad. Sci. PARIS, 278, série A, (1974), 1193. 